\title{
Modeling Self-Agency among People with Schizophrenia: Empirical Evidence for Consumer-Based Recovery
}

\author{
Marcus Yu-Lung Chiu ${ }^{a}$ Larry Davidson ${ }^{b}$ William Tak-Lam Lo ${ }^{c}$ \\ Michael Gar-Chung Yiu ${ }^{d}$ Winnie Wing-Nan $\mathrm{Ho}^{\mathrm{e}}$ \\ ${ }^{a}$ Department of Social Work, Faculty of Arts and Social Sciences, National University of Singapore, Singapore; \\ ${ }^{b}$ Department of Psychiatry, Yale University, New Haven, Conn., USA; ${ }^{C}$ Kwai Chung Hospital, ${ }^{\mathrm{d}}$ Department of \\ Psychiatry, United Christian Hospital, and 'Beat Drugs Fund, Hong Kong, SAR, China
}

\section{Key Words \\ Self-agency $\cdot$ Psychoses $\cdot$ Structural modeling}

\begin{abstract}
Background: Self-agency - the awareness of one's own capacity to make decisions and to engage in deliberate action - is often interfered with or lost during the course of severe mental illness. Most existing literature on self-agency is either of experimental or qualitative nature, and empirical evidence is scanty. Sampling and Methods: This paper draws on a subset of empirical data from a larger recovery study that involved 204 people with schizophrenia in the community. Structural equation models are built to contrast the models with and without the contribution of self-agency. Results: The self-agency factor loads significantly on variables from five major areas of recovery (hope, empowerment, resilience, self-responsibility and self-mastery). Structural equation models show that the incorporation of this self-agency construct has vastly improved the modeling of the adverse effect of stigma on the quality of life of these subjects. The model with self-agency fitted the criteria better, and explained more total variance (increased from 56 to $80 \%)$ for the quality of life of these subjects. Conclusions: Cross-sectional empirical findings appear to support the
\end{abstract}

\begin{tabular}{ll}
\hline KARGER & $\begin{array}{l}\text { ( } 2013 \text { S. Karger AG, Basel } \\
0254-4962 / 13 / 0466-0413 \$ 38.00 / 0 \quad \text { Karger }\end{array}$ \\
E-Mail karger@karger.com & $\begin{array}{l}\text { This is an Open Access article licensed under the terms of the } \\
\text { www.karger.com/psp }\end{array}$ \\
& $\begin{array}{l}\text { Creative Commons Attribution-NonCommercial 3.0 Un- } \\
\text { ported license (CC BY-NC) (www.karger.com/OA-license), } \\
\text { applicable to the online version of the article only. Distribu- } \\
\text { tion permitted for non-commercial purposes only. }\end{array}$
\end{tabular}

claim that self-agency is an important construct that cuts through many dimensions of recovery. Initial discussions are made on the nature and function of self-agency, and its relations with recovery concepts and components.

Copyright $\odot 2013$ S. Karger AG, Basel

\section{Introduction}

Concerns about agency cut across philosophy, psychology, sociology and neuroscience. Irrespective of differences in foci and the terms used, most scientists agree that agency, or more precisely self-agency, is important to our understanding of human actions and actors. Selfagency is the conscious awareness of the fact that one causes at least certain of one's own actions (other actions may be autonomic and not lend themselves to this type of awareness) [1-3]. Such a sense of our own agency is considered fundamental to human self-perception, with Bandura [4], for example, arguing that having a sense of

The major content of this paper has been presented at a symposium: Pathway to Mental Health Recovery - Person-Centred Community Care and Beyond, Hong Kong, 26-28 May 2011. 
our own agency is at the core of our lives as human beings. There is also ample evidence that this sense of selfagency is threatened in different ways by different psychiatric conditions, with affected persons striving very hard to maintain or regain their sense of agency in the face of these threats. In acute states, for example, psychosis is often associated with extremities of either passivity or overestimation of agency in causing actions and their consequences. Recovery from depression has been associated with increased self-agency including being actively involved in decisions about one's own treatment [5]. People with anorexia can be viewed as constantly facing a punishing choice between self-agency and nourishment in order to maintain a schizoid form of self-cohesion [6]. In the case of schizophrenia, a distortion in, or total loss of, a sense of self-agency consistently has been observed and hypothesized to be a core characteristic of the illness since the time of Bleuler [7].

It is important to clarify that self-agency refers to a fundamental level of awareness that provides a necessary foundation for other, more advanced forms of self-awareness that may have received more attention in the social science literature. Without a basic sense of agency, for example, people would not be able to have a sense of their efficacy as an agent, nor would they be able to have any degree of internal locus of control. Self-efficacy and an internal locus of control have been found to be important in coping with, and adaptation to, a range of chronic medical illnesses [8-12]. However, when it comes to psychiatric illnesses like schizophrenia, we may first have to take a step back to consider whether or not there is an enduring and positive sense of self, a basic sense of selfagency, in place as a foundation for these more advanced forms of self-awareness [13].

For instance, neuroscience research has confirmed and elaborated on the long-standing clinical observation that persons with schizophrenia have a diminished or distorted sense of self-agency [14-19], with Frith and Done [18], in particular, suggesting that many of the symptoms of schizophrenia can be attributed to 'a failure to recognize the self in action', resulting in the person attributing his or her own thoughts and actions to others. Jeannerod [20] has recently reviewed this growing body of literature and concluded that the sense of agency is 'deeply impaired' in persons with schizophrenia, with 'first rank symptoms, which represent one of the major features of the disease, testify(ing) to the loss of the ability of schizophrenic patients to attribute their own thoughts, internal speech, covert or overt actions to themselves'. While it is generally believed that this sense of agency relies on multiple cues from multiple sources [21-26], and its development is a complex process, these misattributions are currently thought to be based on imprecise predictions about the sensory consequences of one's actions rather than on processing external agency cues [22-23]. Finally, most researchers believe that the match between anticipated and actual outcomes can enhance the sense of self-agency [24] and that this sense of agency is based on both low-level sensorimotor control between outcome and anticipation, as well as high-level contribution of the prefrontal cortex and personality traits $[8,12]$.

What both neuroscience research and first person accounts suggest is that, at times, there may not be a sense of self-agency and that the regaining of such a sense of agency may be a first and important step in recovery. At the moment, much of this discussion of self-agency is based on neuroscientific hypotheses and elegant experiments, with little attention paid to the actual experiences of persons with schizophrenia. However, further confirmation of the central role of self-agency can be found in the growing literature on personal (as opposed to clinical) recovery $[27,28]$. This literature can be broadly divided into the stage perspective, in which recovery is described as a process that unfolds through progressive stages, and the component perspective, in which a set of essential recovery components are thought to contribute to a more global process that is nonlinear [29]. Stage theories of recovery typically begin with the dawning awareness of a more active self, and move through taking stock of oneself and putting oneself into action, to eventually appealing to the self as a safe haven as an alternative to, or in the midst of, disorder [30]. This form of recovery involves a journey from the decision to take initiative and rebuild independence to reconstructing one's personhood [31], from identity confusion and self-protective withdrawal to setting and actively pursuing meaningful goals, taking control of one's life, and reestablishing a positive sense of self [32].

The component view of recovery is perhaps best exemplified by the National Consensus Statement on Mental Health Recovery developed in 2004 by the US Substance Abuse and Mental Health Services Administration [33]. In this view, recovery as a process consists of ten basic components: recovery involves (1) self-direction and (2) empowerment, is (3) individualized/person-centered and (4) strength-based, requires (5) responsibility, is (6) holistic and (7) nonlinear in nature, and is promoted through (8) hope, (9) respect, and (10) peer support. As is evident from this list, fully half of these components (self-direc- 
tion, empowerment, person-centered, strength-based, and responsibility) address or involve the person's sense of agency. It is clear that self-agency relates to many stages and components of recovery as it has been described and conceptualized by persons with lived experiences of schizophrenia and other serious mental illnesses, even though the exact term has not been directly named by the recovery literature. Only very recently, Lysaker and Leonhardt [34] discussed the broader view of 'agency' in recovery - an embracive term used to describe the basic recognition and experience of 'ownership and authorship of one's thoughts, feelings and actions'. As they rightly point out, the recovery movement is not just a reaction to paternalistic practices in relation to people with mental illness, but a paradigm shift to how these subjects make sense of their lives. They opine that it is important for such coherent, adaptive and subjective experience to be understood by others quantitatively, in spite of the many difficulties encountered in defining operationally the personal aspects of recovery raised by some researchers [35]. Leamy et al. [36] have done a comprehensive review on 97 selected papers on recovery and concluded that the conceptual framework of recovery is 'a theoretically defensible and robust synthesis of people's experiences of recovery in mental illness' and shall be a basis for future research and practice.

If self-agency is so basic to human decision and acts, and is considered to play such a central role in producing recovery, it should have been reflected and traceable in the empirical evidence. However, owing to the differences in the foci, choice of variables and boundaries, inclusion criteria and sampling frame, it is also difficult at this moment to make meaningful comparison between the agency-related constructs that researchers claim explicitly or implicitly. Because of the permeating nature of selfagency, we do not incline to interpret self-agency based on one or two specific variables. Rather, we intend to identify the general construct of self-agency from recovery component variables. This paper draws on a subset of empirical data from a larger recovery study that involved more than 200 people with schizophrenia in the community $[37,38]$. Exploratory factor analysis is carried out to identify the unique self-agency factor out of proxy variables of basic recovery components proposed by the $\mathrm{Na}-$ tional Consensus Statement. Subsequently, structural equation models are built to contrast the models with and without the contribution of this unique factor drawn from the recovery component variables. A common and straightforward model of psychosocial symptoms, stigma and quality of life is put forward, against which the latent factor, self-agency, is added. If the concept of selfagency is a valid one, the analysis should pass these two phases of analysis without major problems when each phase is measured against its own general criteria.

\section{Sampling and Methods}

\section{Scales and Measurement}

The Internalized Stigma of Mental Illness Scale (ISMI) was used. The validity and reliability of ISMI were well established so as to reflect the subjective experience of stigma among populations with mental disorders [39].

The frequency of psychosocial symptoms was measured by a 15-item psychosocial subscale of the Schizophrenia Quality of Life Scale (SQLS) [40]. The subscale has demonstrated excellent internal reliability and validity, with a Cronbach's alpha of 0.93 .

Quality of life was measured by the Hong Kong Chinese World Health Organization Quality of Life Measure abbreviated version, WHOQOL-BREF (HK) [41]. The instrument has a well-established reliability and validity among Chinese people with schizophrenia. The WHOQOL perception was found to be negatively correlated with psychiatric ratings $[42,43]$. The 28 -item WHOQOL-BREF (HK) had four domains and two specific questions that indicated overall quality of life and overall health. The Cronbach's alpha coefficient of the four domains ranged from 0.67 to 0.79 , and the test-retest reliability of items ranged from 0.64 to 0.90 . Subjective rather than objective quality of life indicators were used because they tapped into multiple aspects of actual experiences and provided a more accurate reflection of personal well-being. A closer inspection of the WHOQOL-BREF items found that 17 out of 26 items in the instrument related to the meaningfulness of life (5th, 6th, 19th and 26th items), satisfaction with community (8th, 9th, 13th, 14th, 22nd, 23rd, 24th and 27th items) and human potential (3rd, 7th, 10th, 17th and 18th items) of the respondent. Therefore, it has been used as a proxy indicator of recovery outcome described by the Substance Abuse and Mental Health Services Administration statement.

The personal competence subscale of the Resilience Scale (RS) [44] was used to measure the strength of patients. The internal consistency coefficient of the RS ranged between 0.76 and 0.91 . Empowerment was measured by a 9 -item self-esteem, self-efficacy subscale of the Making Decisions Empowerment Scale (MDES) [45]. The MDES has been validated in the USA and Sweden, and good validity and reliability were found with a Cronbach's alpha of 0.90 [46]. Personal responsibility was measured by the initiative and self-responsibility subscale of the Exercise of Self-Care Agency Scale (ESCA) [47]. The 12-item subscale measured the initiative of the respondents with regard to maintaining their health. The ESCA scale has been validated in subsequent studies [48]. The sense of self-determination was measured by the 7-item Mastery Scale (MS) [49], which assessed the subjective rating of the ability of the respondent to exercise control in the daily course of life. The MS has demonstrated good validity and reliability among people with severe mental disorders $[50,51]$ and the Cronbach's alpha of the MS was estimated to be around 0.73 . Hope was assessed by the Adult State Hope Scale (ASHS), a 6-item instrument that measures a respondent's optimism about achieving his/her goals. The measure demonstrates good internal consistency, with a Cron- 
Fig. 1. Hypothesized base model 1.

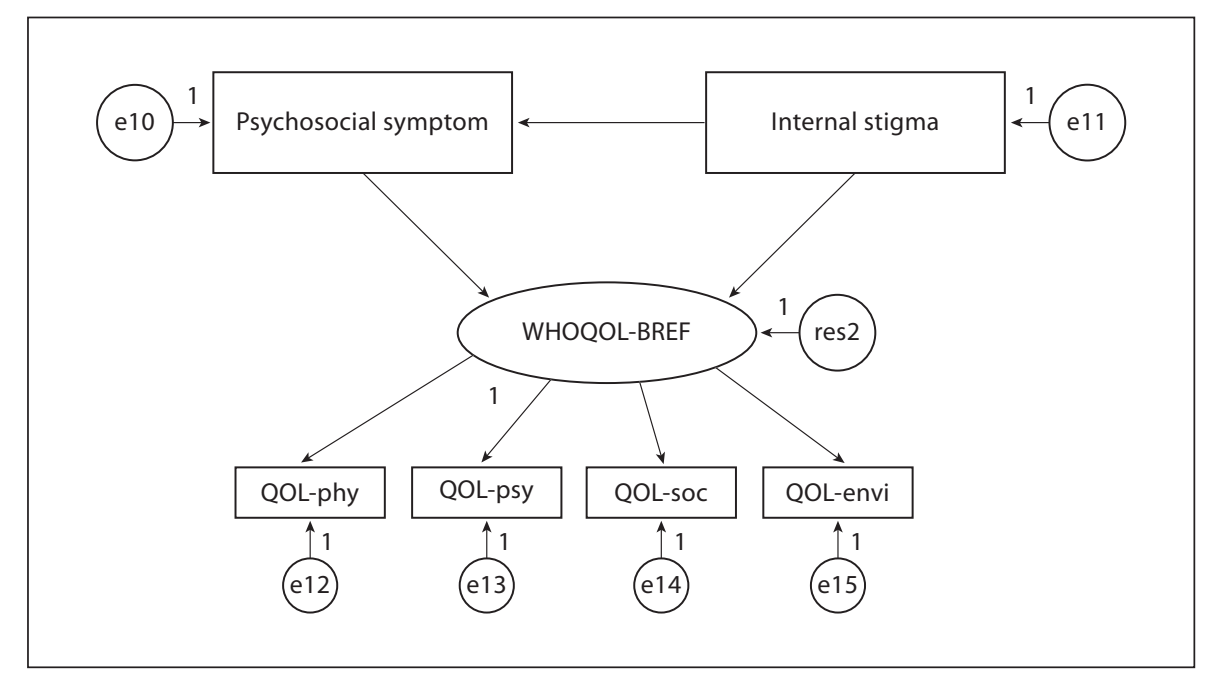

Table 1. Reliability coefficients of scales used

\begin{tabular}{ll}
\hline & Cronbach's alpha (this study) \\
\hline Internal stigma, ISMI & 0.91 \\
Psychosocial symptoms, SQLS & 0.93 \\
Quality of life, WHOQOL_HK & \\
$\quad$ Psychological domain & 0.82 \\
$\quad$ Physical domain & 0.73 \\
$\quad$ Environmental domain & 0.79 \\
$\quad$ Social domain & 0.62 \\
Strength-based, RS & 0.90 \\
Empowerment, MDES & 0.87 \\
Self-responsibility, ESCA & 0.84 \\
Mastery, MS & 0.69 \\
Hope, ASHS & 0.78 \\
\hline
\end{tabular}

bach's alpha ranging from 0.79 to 0.95 [52]. The reliability coefficients of the used inventories are listed in table 1.

\section{Hypothesized Model}

The choice of the base model (fig. 1) is founded on existing evidence that stigma would adversely affect one's quality of life $[53,54]$ and recovery [55]. A psychosocial symptom variable is also pulled in since there is evidence that psychosocial symptoms also adversely affect one's quality of life $[56,57]$, and one's internalized stigma would erode one's self-esteem [58] and subsequently interfere with coping with these psychosocial symptoms. The use of a factor structure (fig. 2) for certain recovery component variables is warranted for two major reasons: firstly, conceptually self-agency is multifaceted and would best be understood as essential competence permeating through many domains; secondly, the power will be improved if latent construct rather than the manifest variables is involved, particularly when the sample size is relatively modest.

\section{Subjects}

The data set contained interview data from more than 200 people aged 18-60 years with schizophrenia spectrum disorder. The mean age of the subjects was $41.6(\mathrm{SD}=9.2)$ and the mean age of the first onset was reportedly $25.4(\mathrm{SD}=7.7)$. Slightly more than half of the subjects (52\%) were male. $61.3 \%$ of the subjects had never married and 56\% received senior high school education. More than three quarters (78\%) of them lived with family members and about one third (32.4\%) were unemployed. Only about one third (32\%) of the subjects had ever engaged in any kind of psychosocial rehabilitation services in the previous 12 months.

\section{Results}

The model fit summary (fig. 3) suggested that the base model (fig. 1) had an overall acceptable fit. Indicators like Normed $\chi^{2}$ (3.44) and Tucker-Lewis index (0.938), comparative fit index (0.967), and a standarized root mean square residual of 0.035 all suggested a good fit. The only exception is the root mean square error of approximation which is slightly below the good-fit level. The base model explained a total of $56 \%$ of variance of the outcome variables. When the self-agency construct was put into the model, the explained variance increased significantly to $80 \%$, without losing the shape of the model fit indicators. The base model was never meant to be a perfect one, as stigma studies have evolved with a better design and the identification of intervening and mediating variables. Model 1 (fig. 1) here served rather as a base for assessing the marginal contribution of the self-agency construct. It is evident that all model fit indicators (Tucker-Lewis index, comparative fit index, standardized root mean 
Fig. 2. Hypothesized structural model 2.

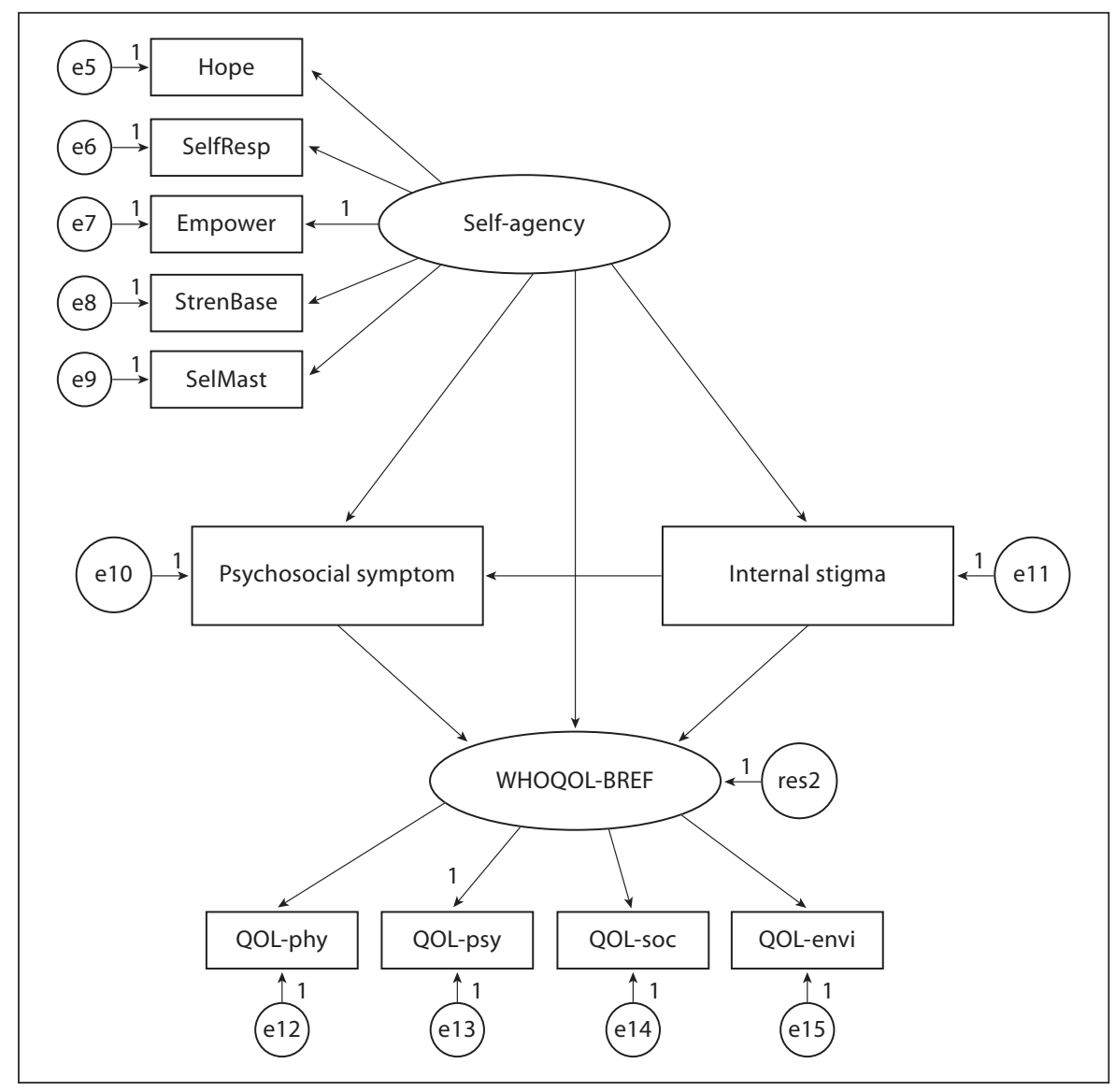

square residual and root mean square error of approximation) improved because of the joining of the self-agency construct. Given a sample size of more than 200 and the involvement of 6 variables, it was therefore well within the acceptable limit of the '1-to-10' rule.

Model 2 (fig. 2) showed a very reasonable pattern of positive and negative relations between the constructs and variables. First, self-agency loaded significantly and positively on the five recovery variables that are indicative of one's competence in different domains. Secondly, as expected, the self-agency construct loaded negatively and significantly on the two base model variables - internal stigma and psychosocial symptoms - though selfagency acted to a much stronger magnitude on internal stigma than on psychosocial symptoms. The better one's sense of control and mastery, the better one will be at coping with stigma and psychosocial symptoms. Thirdly, the self-agency construct contributed positively, significantly and directly to one's quality of life. It is evident that selfagency is a power construct that acts both directly and indirectly in determining one's quality of life.

\section{Discussion}

Some theorists may doubt whether there exists any truly autonomous decision and behavior [59-61], whether researchers have overromanticized Western conceptions of the individual agency, or whether nonconsciousness rather than one's sense of agency is part of, or the key driving force behind, human choice and behavior [62-64]. These doubts will continue but have provided little clue as to the possible directions of remedies and development towards the recovery of people with severe mental illness. This study chose to look at the argument from another side: if self-agency is something real and happening, can it be empirically identified from the recovery components? The findings from this study are affirmative, though never meant to be conclusive. One may argue what the factor really is, and it may not necessarily be self-agency as we called it. We long to be refuted conceptually and empirically. Judging from its significant relations with self-responsibility, hope, strength/resilience, empowerment and sense of mastery, it would be difficult to name it in a dif- 


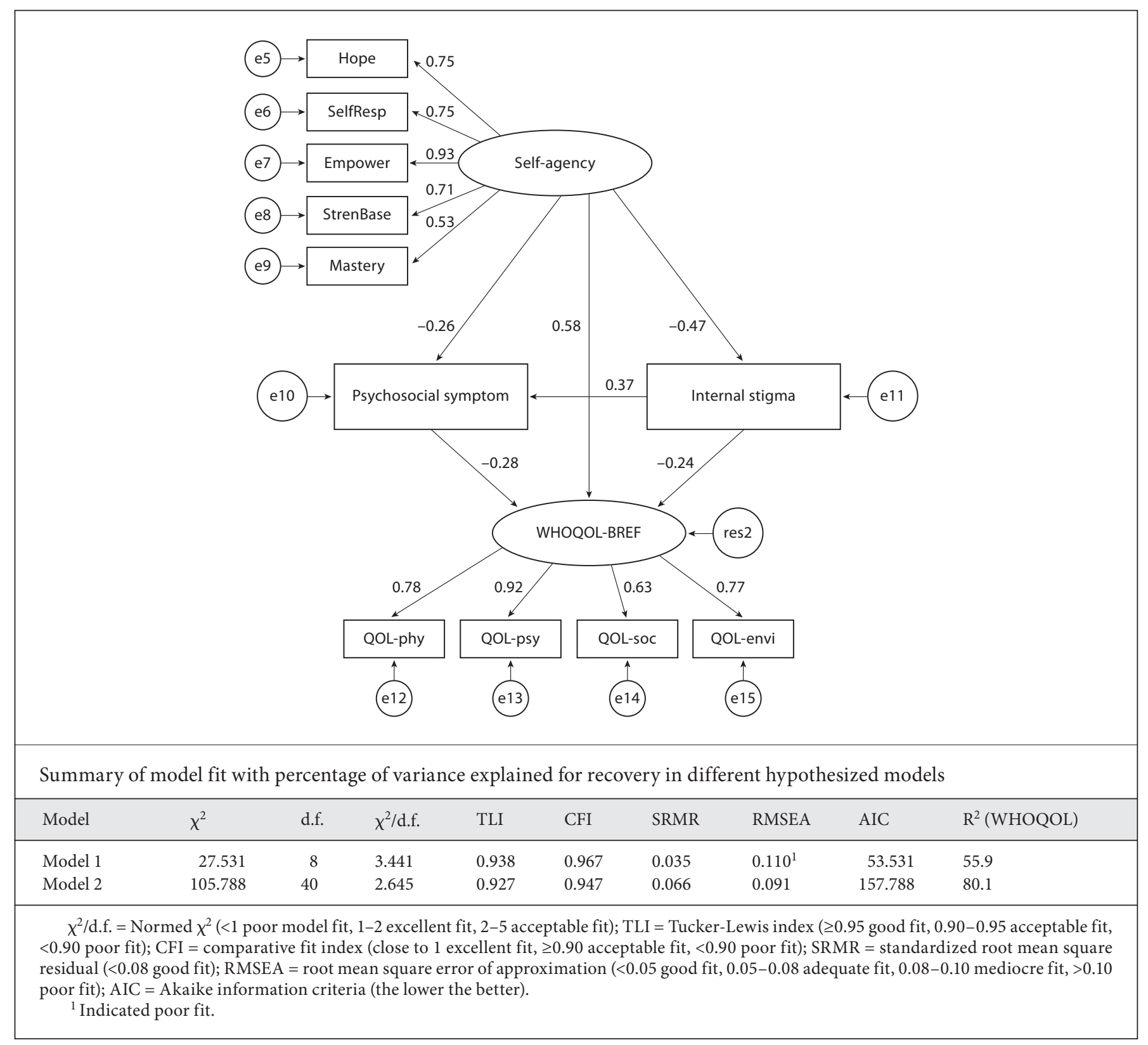

Fig. 3. Self-agency model with standardized parameter estimates.

ferent way. It is reasonable initially to call it self-agency. The empirical models have helped us at least to better appreciate that self-agency may possibly be a composite of many strengths and competences. Although the exact relation between self-agency and each recovery component involved is unclear, this new construct can be identified empirically. We now have a basic understanding that this core competence/attribute may counteract stigma and enhance one's quality of life, and there is much room for discussion on how programs could be designed and implemented in such a way that brings similar results. Until now different programs and approaches have been designed to realize different goals (strength-based, empowerment, hope instillation, etc.). If only we come to know more about the nature of this construct and its working with the different recovery components, we will be able to design more targeted and holistic programs. 


\section{Conclusions}

Since the interview data collected had no randomized design (due to practical problems), it is difficult to draw comfortable generalizations. Further studies, with a better design, are warranted. It will be another challenge to see how these findings, though initial, could be translated to inform our practices. Some earlier programs such as knowledge-based, participatory empowerment training with caregivers have indicated that self-agency has to be impacted before empowerment takes place [65]. It is perhaps the right time to reexamine existing practice, to further research the construct, and to invite more discussion on what makes one's recovery a meaningful process.

\section{References}

1 Ahearn LM: Language and agency. Annu Rev Anthropol 2001;30:109-137.

$\checkmark 2$ Aarts H, Custers R, Marien H: Priming and authorship ascription: when nonconscious goals turn into conscious experiences of selfagency. J Pers Soc Psychol 2009;96:967-979.

3 Pacherie E: Self-Agency; in Gallagher S (ed): The Oxford Handbook of the Self. Oxford, Oxford University Press, 2011, pp 440-462.

4 Bandura A: Social cognitive theory: an agentic perspective. Ann Rev Psychol 2001;52:126.

5 Vidler HC: Women making decisions about self-care and recovering from depression. Womens Stud Int Forum 2005;28:289-303.

6 Sella YS: Without skin, bones with no flesh: bodily aspects of the self in the treatment of women patients with restrictive anorexic eating patterns. Int J Psychother 2003;8:37.

$\checkmark 7$ Moskowitz A, Heim G: Eugen Bleuler's dementia praecox or the group of schizophrenias (1911): a centenary appreciation and reconsideration. Schizophr Bull 2011;37:471479.

8 Slachevsky A, Pillon B, Fourneret P, Renié L, Levy R, Jeannerod M, Dubois B: The prefrontal cortex and conscious monitoring of action: an experimental study. Neuropsychologia 2003;41:655-665.

9 Kircher TT, Leube DT: Self-consciousness, self-agency, and schizophrenia. Conscious Cogn 2003; 12:656.

10 Stanley KE, Friston KJ, Frith CD: Dysconnection in schizophrenia: from abnormal synaptic plasticity to failures of self-monitoring. Schizophr Bull 2009;35:509-527.

-11 Belayachi S, Van der Linden M: Feeling of doing in obsessive-compulsive checking. Conscious Cogn 2010;19:534-546.

12 Spengler S, von Cramon DY, Brass M: Was it me or was it you? How the sense of agency originates from ideomotor learning revealed by fMRI. Neuroimage 2009;46:290-298.

13 Davidson L, Strauss JS: Sense of self in recovery from severe mental illness. Br J Med Psychol 1992;65:131-45.
14 Synofzik M, Thier P, Leube DT, Schlotterbeck P, Lindner A: Misattributions of agency in schizophrenia are based on imprecise predictions about the sensory consequences of one's actions. Brain 2010;133:262-271.

15 Voss M, Moore J, Hauser M, Gallinat J, Heinz A, Haggard P: Altered awareness of action in schizophrenia: a specific deficit in predicting action consequences. Brain 2010;133: 3104-12.

16 Frith, CD: The positive and negative symptoms of schizophrenia reflect impairments in the perception and initiation of action. Psychol Med 1987;17:631-648.

17 Frith CD, Allen HA: The skin-conductance orienting response as an index of attention. Biol Psychol 1983;17:27-39.

18 Frith CD, Done DJ : Routes to action in reaction-time tasks. Psychol Res 1986;48:169177.

19 Frith CD, Done DJ: Experiences of alien control in schizophrenia reflect a disorder in the central monitoring of action. Psychol Med 1989;19:359-363.

20 Jeannerod M: The sense of agency and its disturbances in schizophrenia: a reappraisal. Exp Brain Res 2009;192:527-532.

21 Bayne T, Pacherie E: Narrators and comparators: the architecture of agentive selfawareness. Synthese 2007;159:475-491.

22 Allagher S: Simulation trouble. Soc Neurosci 2007;2:353-365.

23 Knoblich G, Repp BH: Inferring agency from sound. Cognition 2009;111:248-262.

24 Pacherie E: The phenomenology of action: a conceptual framework. Cognition 2008; 107: 179-217.

25 Sato A: Both motor prediction and conceptual congruency between preview and action-effect contribute to explicit judgment of agency. Cognition 2009;110:74-83.

26 Synofzik M, Vosgerau G, Newen A: I move, therefore I am: a new theoretical framework to investigate agency and ownership. Conscious Cogn 2008;17:411-424.

27 Anthony WA: Recovery from mental illness: the guiding vision of the mental health system in the 1990s. Innovations Res 1993;2: $17-24$.
28 Davidson L, Rakfeldt J, Strauss JS: The Roots of the Recovery Movement in Psychiatry: Lessons Learned. Chichester, Wiley-Blackwell, 2010.

$\checkmark 29$ Bobes J, Ciudad A, Álvarez E, San L, Polavieja P, Gilaberte I: Recovery from schizophrenia: results from a 1-year follow-up observational study of patients in symptomatic remission. Schizophr Res 2009;115:58-66.

-30 Andresen R, Caputi P, Oades L: Stages of recovery instrument: development of a measure of recovery from serious mental illness. Aust NZ J Psychiatry 2006;40:972-980.

- 31 Baxter EA, Diehl S: Emotional stages: consumers and family members recovering from the trauma of mental illness. Psychiatr Rehabil J 1988;21:349-355.

32 Andresen R, Oades L, Caputi P: The experience of recovery from schizophrenia: towards an empirically validated stage model. Aust NZ J Psychiatry 2003;37:586-594.

33 Substance Abuse and Mental Health Services Administration: National Census Statement on Mental Health Recovery 2006. National Mental Health Information Center, US Department of Health and Human Services, 2006.

34 Lysaker PH, Leonhardt BL: Agency: its nature and role in recovery from severe mental illness. World Psychiatry 2012;11:165-166.

-35 Wallcraft J: Consumer models of recovery: can they survive operationalism? World Psychiatry 2012;11:166-167.

36 Leamy M, Bird V, Boutillier CL, Williams J, Slad M: Conceptual framework for personal recovery in mental health: systematic review and narrative synthesis. Br J Psychiatry 2011; 199:445-452.

37 Chiu MY, Ho WW, Lo TL, Yiu MG: Operationalization of the SAMHSA Model of Recovery: a quality of life perspective. Qual Life Res 2010;19:1-13.

38 Ho WW, Chiu MY, Lo TL, Yiu MG: Recovery components as determinants of the healthrelated quality of life among patients with schizophrenia: a structural equation modeling analysis. Aust NZ J Psychiatry 2010;44: 71-84. 
-39 Ritsher BJ, Otilingam PG, Grajales M: Internalized stigma of mental illness: psychometric properties of a new measure. Psychiatry Res 2003;121:31-49.

-40 Wilkinson G, Hesdon B, Wild D, Cookson R, Farina C, Sharma V, Fitzpatrick R, Jenkinson C: Self-report quality of life measure for people with schizophrenia: the SQLS. Br J Psychiatry 2000;177:42-46.

41 Leung KF, Wong WW, Tay MS, Chu MM, Ng SS: Development and validation of the interview version of the Hong Kong Chinese WHOQOL-BREF. Qual Life Res 2005; 14 1413-1419.

-42 Chan G, Ungvari GS, Shek DT, Leung JJ: Hospital and community-based care for patients with chronic schizophrenia in Hong Kong: quality of life and its correlates. Soc Psychiatry Psychiatr Epidemiol 2003;38: 196-203.

43 Chan S, Yu IW: Quality of life of clients with schizophrenia. J Adv Nurs 2004;45:72-83.

44 Wagnild GM, Young HM: Development and psychometric evaluation of the Resilience Scale. J Nurs Meas 1993:1:165-178.

-45 Rogers ES, Chamberlin J, Ellison ML, Crean T: A consumer-constructed scale to measure empowerment among users of mental health services. Psychiatr Serv 1997;48:1042-1047.

46 Hansson L, Bjorkman T: Empowerment in people with a mental illness: reliability and validity of the Swedish version of an empowerment scale. Scand J Caring Sci 2005; 19: 32-38.

-47 Kearney BY, Fleischer BJ: Development of an instrument to measure exercise of self-care agency. Res Nurs Health 1979;2:25-34.
48 Riesch SK, Hauck MR: The exercise of selfcare agency: an analysis of construct and discriminant validity. Res Nurs Health 1988;11: 245-255.

49 Pearlin L, Schooler C: The structure of coping. J Health Soc Behav 1978;19:2-21.

50 Bengtsson-Tops A: Mastery in patients with schizophrenia living in the community: relationship to sociodemographic and clinical characteristics, needs for care and support, and social network. J Psychiatr Ment Health Nurs 2004;11:298-304.

51 Rosenfield S: Factors contributing to the subjective quality of life of the chronic mentally ill. J Health Soc Behav 1992;33:299-315.

52 Snyder CR, Sympson SC, Ybasco FC, Borders TF: Development and validation of the State Hope Scale. J Pers Soc Psychol 1996;70: 321-335.

53 Graf J, Lauber C, Nordt C, Rüsch P, Meyer PC, Rössler W: Perceived stigmatization of mentally ill people and its consequences for the quality of life in a Swiss population. J Nerv Ment Dis 2004; 192:542-547.

54 Lee S, Lee MT, Chiu MY, Kleinman A: Experience of social stigma by people with schizophrenia in Hong Kong. Br J Psychiatry 2005; 186:153-157.

55 Perlick DA, Rosenheck RA, Clarkin JF, Sirey JA, Salahi J, Struening EL, Link BG: Stigma as a barrier to recovery: adverse effects of perceived stigma on social adaptation of persons diagnosed with bipolar affective disorder. Psychiatr Serv 2001;52:1627-1632.

6 Ho BC, Nopoulos P, Flaum M, Arndt S, Andreasen NC: Two-year outcome in first-episode schizophrenia: predictive value of symptoms for quality of life. Am J Psychiatry 1998;155:1196-1201.
57 Lysaker PH, Buck KD, Hammoud K, Taylor AC, Roe D: Associations of symptoms, psychosocial function and hope with qualities of self-experience in schizophrenia: comparisons of objective and subjective indicators of health. Schizophr Res 2006;82:241-249.

58 Lysaker PH, Tsai J, Yanos P, Roe D: Associations of multiple domains of self-esteem with four dimensions of stigma in schizophrenia. Schizophr Res 2008;98:194-200.

59 Loyal S, Barnes B: 'Agency' as a red herring. Philos Soc Sci 2001;31:507-524.

60 Fuchs S: Beyond agency. Sociol Theory 2001; 19:24-40.

61 Meyer JW, Jepperson RL: The 'actors' of modern society: the cultural construction of social agency. Sociol Theory 2000;18:100120 .

62 Custers R, Aarts H: The unconscious will: how the pursuit of goals operates outside of conscious awareness. Science 2010;329:4750 .

63 Aarts H, Custers R, Marien H: Priming and authorship ascription: when nonconscious goals turn into conscious experiences of selfagency. J Pers Soc Psychol 2009;96:967-979.

64 Aarts H, van den Bos K: On the foundations of beliefs in free will: intentional binding and unconscious priming in self-agency. Psychol Sci 2011;22:532-537.

65 Clarke N: Training as a vehicle to empower carers in the community: more than a question of information sharing. Health Soc Care Community 2001;9:79-88. 